\title{
Towards a european atlas of natural radiation: Goal, status and future perspectives
}

\author{
M. De Cort ${ }^{1}$, V. Gruber ${ }^{1}$, T. Tollefsen ${ }^{1}$, P. Bossew ${ }^{2}$ and A. Janssens ${ }^{3}$ \\ ${ }^{1}$ European Commission, JRC, Institute for Transuranium elements, 21027 Ispra (VA), Italy \\ 2 German Federal Office for Radiation Protection, 10318 Berlin, Germany \\ ${ }^{3}$ European Commission, DG ENER, Radiation Protection Unit, \\ 2920 Luxembourg, Luxembourg
}

\begin{abstract}
One of the tasks of the European Commission (EC) under the Euratom Treaty is to collect, validate and provide information about the levels of radioactivity in the environment. In order to offer to the public a more balanced view on the annual dose that it may receive from environmental radioactivity, a few years ago we decided to explore the feasibility of preparing a European Atlas of Natural Radiation. By now 21 European countries have already provided indoor radon data, and efforts continue to extend this information to more countries. In addition, we started to investigate the feasibility of a "geogenic radon map", which would show "what earth delivers" in terms of potential radon hazard. In this paper we present the current state of the art of preparing the Atlas and provide detailed statistics for the results already obtained. The current efforts are still focussed on radon, but also progress on other components, such as cosmic rays and terrestrial gamma radiation, will be presented and discussed.
\end{abstract}

\section{INTRODUCTION}

The EC develops and operates systems for collecting, validating and reporting information about the levels of radioactivity in Europe's environment on a continuous basis for routine and emergency conditions. In this context, in 1998 the EC published the "Atlas of Caesium deposition on Europe after the Chernobyl accident" [1] with the aim to offer more detailed information on an anthropogenic radionuclide to a wider audience. In order to provide the public with a more balanced view on the annual dose that it may receive from environmental radioactivity, a few years ago we decided to explore the feasibility of preparing a European Atlas of Natural Radiation (EANR). An earlier attempt, resulting in a Radiation Atlas for Natural Sources, was published in 1993, but did not include data from Central and Eastern European countries and was made on administrative rather than geographical basis [2]. Furthermore, the EANR should provide reference material and generate harmonized data which may be used by the scientific community for e.g. epidemiological or radiological studies, and support and stimulate communication within the scientific community on a complex issue, such as radon mapping or definition of hazard and risk.

\section{A EUROPEAN INDOOR RADON MAP}

We started with indoor radon, since this is, in most cases, the most important contributor to the population dose. This radioactive gas, or more precisely some of its radioactive progenies, is also considered to be the leading cause of lung cancer, second only to smoking [3]. Therefore, given its relevance to public health, a number of European countries have implemented regulations to identify radon-prone areas, where prevention and mitigation are considered particularly important. When the Joint Research Centre (JRC) of the European Commission (EC) published an overview of these radon surveys in 2005 [4], it showed that measurement techniques and mapping strategies differ between all 


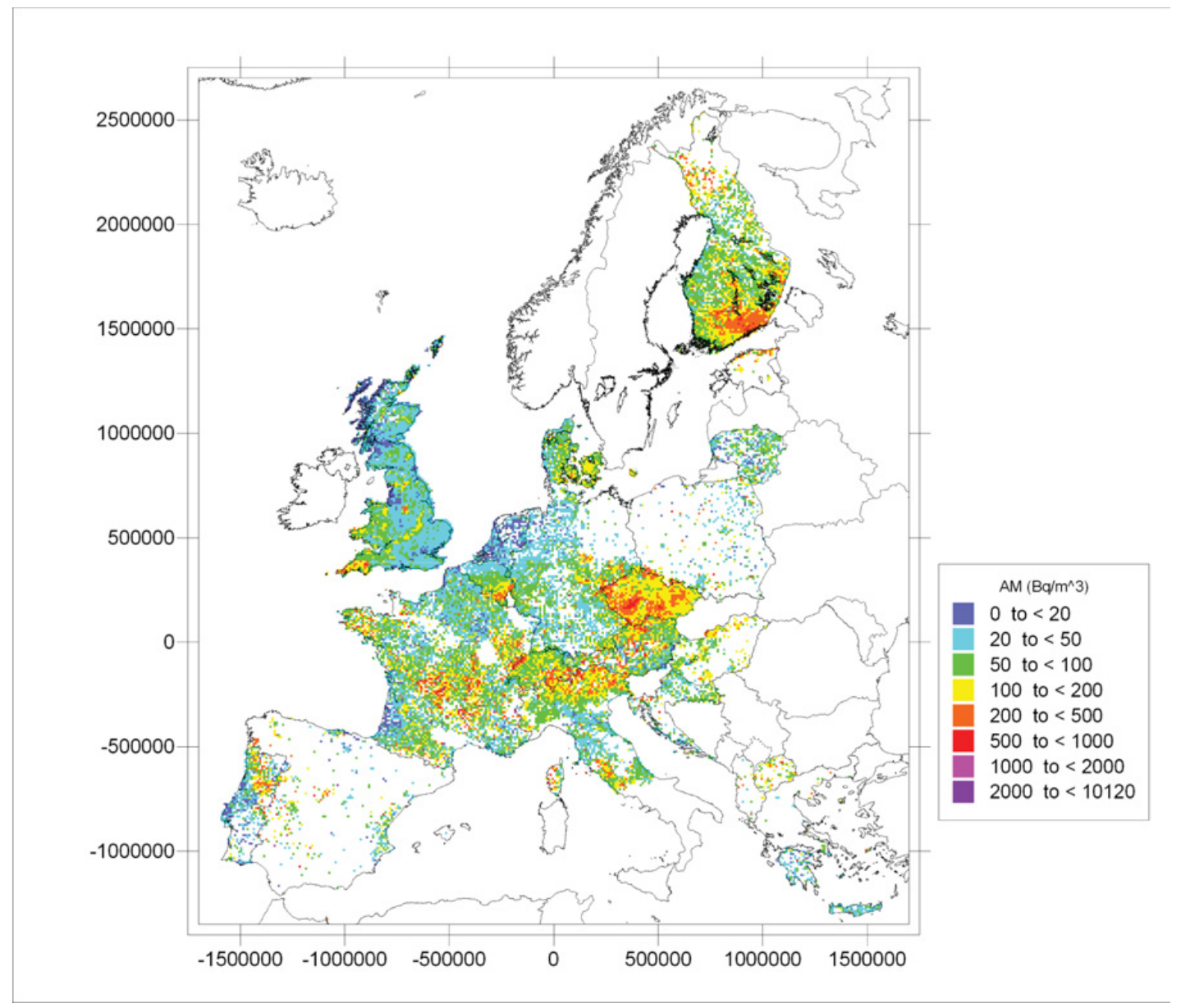

Figure 1. Arithmetic means (AMs) of indoor radon concentration in ground-floor rooms in $10 \mathrm{~km} \times 10 \mathrm{~km}$ cells. Data available until April 2011 included. Axis units: m.

countries; in fact, no two countries use the same approach. As a consequence, collecting information on radon data from different countries and integrating them into a common framework triggers a number of conceptual and technical challenges.

The methods and procedures applied to collect and process the raw data have already been described in more detail in [5] and [6].

By April 2011, data have been received from 21 participating countries. Figure 1 shows the arithmetic means (AMs) of annual average indoor radon concentration in ground-floor rooms over $10 \mathrm{~km} \times 10 \mathrm{~km}$ cells across Europe. The map has nearly 18,000 non-empty cells with data, based on nearly 800,000 measurements in total. Still, there are many empty cells. This European Indoor Radon Map (EIRM) thus reflects the status of national surveys of indoor radon monitoring in Europe.

The map reveals a spatial trend in indoor radon concentrations, i.e. regions with higher and lower radon concentrations; this is mainly due to varying geology. High radon areas are found in the Bohemian Massif, the Fennoscandian Shield, crystalline rocks of the South Alps, the Swiss Jura, the Ardennes, the granites of the Iberian Peninsula and Cornwall and some volcanic areas in Central Italy, among other regions.

Figure 2 illustrates the AM and median ( \pm median absolute deviation, MAD) of the AMs of the cells for each country. The radon concentrations vary strongly within most countries (see also Figure 1) due 


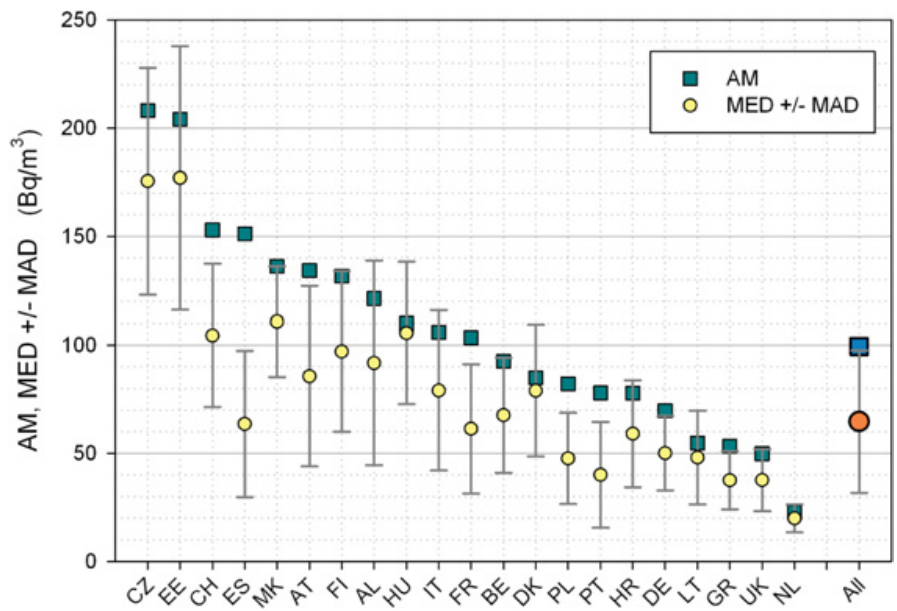

Figure 2. Estimated spatial mean radon concentrations per country. AM - arithmetic mean over AMs within cells; MED - medians over AMs within cells; MAD - mean absolute deviation $=\operatorname{MED}\left\{\left|\mathrm{AM}_{i}-\operatorname{MED}\left(\mathrm{AM}_{i}\right)\right|\right\}$, where $\mathrm{AM}_{i}=\mathrm{AM}$ in cell $i$.

Table 1. Descriptive statistics of the dataset on which the European indoor radon map is based, as of April 2011. $\mathrm{CV}$ - coefficient of variation, $\mathrm{CV}=$ standard deviation / $\mathrm{AM}$.

\begin{tabular}{|l|l|}
\hline Number of non-empty cells (including UK \& NI) & 17,922 \\
\hline Total number of measurements & 797,051 \\
\hline Measurements per cell, MED \pm MAD & $5 \pm 4$ \\
\hline Min/Max number of measurements per cell & $1 / 23,993$ \\
\hline Cell mean, AM \pm CV\% (without NI - $n=17,748)$ & $99.4 \mathrm{~Bq} / \mathrm{m}^{3} \pm 153 \%$ \\
\hline Percentage Cell AM $>400 \mathrm{~Bq} / \mathrm{m} 3$ & $2.99 \%$ \\
\hline Percentage Cell AM $>300 \mathrm{~Bq} / \mathrm{m} 3$ & $4.34 \%$ \\
\hline Percentage Cell AM $>100 \mathrm{~Bq} / \mathrm{m} 3$ & $30.85 \%$ \\
\hline CV within cells, MED $\pm \mathrm{MAD}$ & $(54 \pm 28) \%$ \\
\hline GSD within cells, MED \pm MAD & $1.85 \pm 0.38$ \\
\hline
\end{tabular}

to geology. For instance, the AM of Spain is more than twice the median, because some very high radon concentrations in regions of granites of the Iberian Peninsula influence the AM more than the median; similarly also for Portugal. The figure shows that countries are affected by the radon problem to a very different extent: for instance, the medians of the AMs of all the non-empty cells in the Czech Republic approaches $180 \mathrm{~Bq} / \mathrm{m}^{3}$, which is nearly 10 times that of the Netherlands. The AM of all non-empty cells in Europe (participating countries) is $99 \mathrm{~Bq} / \mathrm{m}^{3}$, while the median is $65 \mathrm{~Bq} / \mathrm{m}^{3}$. Note, however, that this spatial mean (mean over cells) is different from the mean over individual measurements $\left(\mathrm{AM}=136 \mathrm{~Bq} / \mathrm{m}^{3}\right)$, from the mean over country-means $\left(\mathrm{AM}=106 \mathrm{~Bq} / \mathrm{m}^{3}\right)$ and again, in general, from the population density-weighted mean (no value available so far). Only the latter quantity is a proxy of exposure, to some extent, and thus for radiological significance. Also note that ground-floor concentrations are in general higher than the ones in higher floors, and that most people actually do not live in ground-floor rooms. Ground floor has been chosen as reference for pragmatic reasons, i.e. because most data are available for ground floor.

Table 1 lists some statistical parameters of the dataset which underlies the map. The number of non-empty cells varies because the dataset provided for the UK and Northern Ireland (NI) includes measurements other than from ground floor. 
The cumulative frequency distribution of the arithmetic means of the 17,748 non-empty cells (without NI) shows an approximate log-normality with some extremes. (For further discussion of the log-normality of the data, see [7].) Half of the non-empty cells of Europe have an AM below $60 \mathrm{~Bq} / \mathrm{m}^{3}$. For $99.9 \%$ of the cells an $\mathrm{AM}$ below $1000 \mathrm{~Bq} / \mathrm{m}^{3}$ can be expected; for $90 \%$, below $200 \mathrm{~Bq} / \mathrm{m}^{3}$.

The number of measurements per cell and coverage of territory vary widely within the participating countries of Europe. These factors clearly influence the statistics and reliability of the map (Figure 1). Large areas with high sampling density are found in e.g. the Czech Republic, Austria, Switzerland, North Italy, Belgium, the UK and South Finland. In total, for all the participating countries the median number of measurements $( \pm \mathrm{MAD})$ per cell is $5 \pm 4$.

\section{A EUROPEAN GEOGENIC RADON MAP}

Indoor radon concentrations are subject to human activity, natural (geological) and anthropogenic factors such as construction types, building materials, living habits and meteorology, and are temporally variable and characteristic for each particular house (these factors may still show regional trends caused by regionally predominant climate and cultural preferences). For instance, two differently built houses on the same geological ground will have different average indoor radon concentrations, as will two identically built houses on the same ground, but with different living habits of the inhabitants. As another case, improving the insulation of a house can influence its indoor radon concentration. Therefore, one is interested in mapping a quantity which is closer to hazard, and which measures "what earth delivers" in terms of radon, irrespective of anthropogenic factors and temporally constant over a geologic timescale. This quantity, or spatial variable, is called geogenic radon potential, and the idea of the European Geogenic Radon Map (EGRM) is to map such a variable.

A report with contributions from experts in different fields (geologists, physicists, etc.) is now in preparation. It collects a status of knowledge in the relevant scientific fields and should be the basis for future discussions and decisions how to proceed with the EGRM. As a next step, to decide on the final strategy, a meeting is planned at the JRC (Ispra) for autumn 2011.

The geogenic radon potential map will be created in the $10 \mathrm{~km} \times 10 \mathrm{~km}$ grid using the ETRS-LAEA projection (see [8]), similar to that used for the EIRM. The experts compiled a list of variables which could be used as input variables to define the target variable "geogenic radon potential" in a grid cell. On one hand, selected variables include geology data (geological units, lineaments, special geological features), which are polygons and line data. On the other, there are (radiometry) point data like soil gas radon concentration, geochemical concentrations $(\mathrm{U}, \mathrm{Ra}, \mathrm{Th})$ in soils, geophysical data (eU by airborne gamma), external dose rate, soil permeability and outdoor radon concentration. At this stage of the project the availability of these data (geo-referenced, electronically accessible, data protected, etc.) in the countries is under investigation. Besides, generally available data on a European scale are checked for usability as input variables or layers for the EGRM. For example the OneGeology project [9] has collected geological data (age, lithology) from all participating countries and made them available. These data can be used as a basis by the experts to simplify and classify geological units regarding radon risk, which can then be used as one input variable (geology) to estimate the geogenic radon potential in a grid cell. But of course these classifications need supporting measurement data and surveys, knowledge and experience, and this will be a continuous point of discussion among the experts.

One key question for the EGRM is how to define appropriately the target variable which quantifies the geogenic radon potential. In international practice there have been various approaches, depending on the data realm. In most cases one tries to identify a multivariate way for defining a target quantity, called radon potential or radon index. The rationale is that in general there is more information available than just radon concentrations in indoor or soil air. The question is how to merge different kinds of data, including possibly incomplete sets and data of varying quality, into one target variable. Different approaches have been suggested to use for the EGRM map by the experts till now. Apart from the multivariate classification approach (also called cross-tabulation), mentioned above and further 
explained below, whose feasibility and robustness is proven, possible approaches are: (1) a purely analytical approach to defining a "radon hazard index" out of controlling input quantities, as suggested in the Czech Republic [10]; (2) a "posterior" approach which defines the radon potential as normalized indoor concentration; (3) exceedance probability of indoor concentration, given defined factors; and (4) a probabilistic approach, where no functional dependencies are used, but instead the fact that the observed data, seen as multivariate field, have statistical correlation as intrinsic property, since they represent physically dependent quantities. Therefore the joint distribution could be used as a simple radon index.

The most established way to define and map a radon potential appears to be classification by assigning scores to intervals of values (e.g. for radon concentration) or categories (for geology). It is therefore also a very good candidate for the EGRM. In a multi-dimensional table, "rows" in any dimension denote classes, like geological ones (nominal variables), or classes of concentration in soil gas, or soil permeability (ordinal classes). This approach is widely used; e.g. Germany [11], Czech Republic [10], France [12], USA [13]. Uncertainty can be included by generating "uncertainty classes", as demonstrated in the US radon map [13]. Missing inputs to the table result in higher uncertainty. Since the US approach appears to be the most general of this type, so far, and also includes a classification of uncertainty, and has also proven robust, it was suggested at the Prague meeting in 2010 that the experts should see if it can be adapted to the European data situation.

\section{FUTURE PERSPECTIVES AND CONCLUSIONS}

The JRC will continue to work on the EIRM by collecting data from new participants to the project and from established participants as they complement or improve their data, and will publish updated versions of the map from time to time. Whereas some countries have finished their survey years ago, there are those which have not even started. Yet others (e.g. Ireland and Slovenia) had survey strategies which produced datasets incompatible with the scheme of the European map. During data processing it was noted that the overall picture seems plausible and the results are mostly homogeneous. Nevertheless, heterogeneities appear across borders. In an effort to understand and compare the data better and potentially improve the maps, in summer 2010 the JRC sent a questionnaire to the data providers, asking them about survey design, measurements techniques and statistical processing. Their information will allow the JRC to investigate the impact of these parameters on the radon concentration. It should also help to identify possible datasets which do not fully comply with the technical specifications and to interpret cross-border effects, and how to handle these.

The next step for the EGRM is to finish the progress report as a basis for future discussions and decisions how to proceed with the map. Besides, checking the availability and usability of data in the countries as input variables will continue. The experts are working on simplified, radon-relevant, geological classifications and adapt a classification scheme usable for the European data.

As a third part of radon, an outdoor radon map is planned. Outdoor radon is the result of the flux from the ground and the dispersion in the atmosphere. Outdoor radon usually has no radiation protection or dose relevance for the public, but knowledge of the outdoor radon concentration can be used to estimate indoor radon and assess the anthropogenic influence and can be a helpful input variable for the EGRM. Outdoor radon data are available in several European countries. A reasonable grid and method for mapping is under discussion, and a "cooking recipe" according to the German experience will be developed.

The EANR will also contain maps and information other than on radon. Some first draft maps and calculations were already produced with the effective annual dose caused by cosmic radiation, taking into account neutrons, directly ionizing particles and photons estimated according to [14] and based on a $1 \mathrm{~km} \times 1 \mathrm{~km}$ grid Shuttle Radar Topography Mission (SRTM) elevation map. Further calculations with different models and with different grids will be carried out. In contrast to the other maps, no 
measurement and input data from the countries are needed for these maps, and calculations can therefore be realized without involving the countries.

Other maps are planned, such as terrestrial gamma radiation, which could be estimated out of gamma dose rate data available from the EURDEP system [15]. Another approach will be a multivariate estimation out of different datasets (e.g. geological data, soil data, airborne gamma). Some ideas exist for further maps, e.g. geochemical maps or water maps, but it must be discussed whether they are feasible and reasonable. It has to be clarified whether enough data exist for those maps in the countries, and for some variables (e.g. groundwater) mapping is very complex.

A long-term overall goal of the project is to combine all maps created and all data collected and calculate a total dose for the population caused by natural radioactivity in a defined grid and display a map of total dose by natural radiation.

\section{Acknowledgments}

The authors are grateful to all direct and indirect contributors and national data providers to the European radon maps, for without their help, this work would not have been possible.

\section{References}

[1] De Cort M., Dubois G., Fridman Sh. D., Germenchuk M.G., Izrael Yu. A., Janssens A., Jones A. R., Kelly G. N., Kvasnikova E. V., Matveenko I. I., Nazarov I. M., Pokumeiko Yu. M., Sitak V.A., Stukin E. D., Tabachny L. Ya., Tsaturov Yu. S. and Avdyushin S.I., Atlas of Caesium Deposition on Europe after the Chernobyl Accident (EUR report nr. 16733, EC, Office for Official Publications of the European Communities, Luxembourg, 1998)

[2] Radiation Atlas: natural sources of ionizing radiation in Europe (EC, Office for Official Publications of the European Communities, Luxembourg, 1993)

[3] Darby S., Hill D., Auvinen A., Barros-Dios J.M., Baysson H., Bochicchio F., Deo H., Falk R., Forastiere F., Hakama M., Heid I., Kreienbrock L., Kreuzer M., Lagarde F., Mäkeläinen I., Muirhead C., Oberaigner W., Pershagen G., Ruano-Ravina A., Ruosteenoja E., Schaffrath Rosario A., Tirmarche M., Tomásek L., Whitley E., Wichmann H.-E. and Doll R., Radon in homes and risk of lung cancer: collaborative analysis of individual data from 13 European case-control studies. BMJ, doi:10.1136/bmj.38308.477650.63. (2005)

[4] Dubois G., An overview of radon surveys in Europe (Report EUR 21892. EC,Office for Official Publications of the European Communities, Luxembourg, 2005) pp. 168

[5] Dubois G., Bossew, P., Tollefsen, T. and De Cort, M., J Environmental Radioactivity 101 (2010) 786-798. doi:10.1016/j.jenvrad.2010.03.007.

[6] Tollefsen,T., Gruber V., Bossew P. and De Cort M., Status of the European Indoor Radon Map., Radiation Protection and Dosimetry. Advanced access published 2 April 2011. doi:10.1093/rpd/ncr072.

[7] Bossew, P. J Environmental Radioactivity 101 (2010) 826-834.

[8] Annon, A., Luze, C., Guble, E., Ihd, J. (Eds.) (2001). Map Projections for Europe. European Communities. 131 pp. http://www.ec-gis.org/sdi/publist/pdfs/annoni-etal2003eur.pdf (last accessed 14 June 2011).

[9] OneGeology project. http://www.onegeology.org (last accessed 14 June 2011).

[10] Nezna, M., Nezna, M., Matoli, M., Barne, I., Miksov, J. (2004). The new method for assessing the radon risk of building sites, Czech Geological Survey Special Papers, Vol.16, Czech Geological Survey, Prague, http://www.radon-vos.cz/pdf/metodika.pdf (last accessed 14 June 2011).

[11] Kemsk, J., Sieh, A., Stegeman, R. and Valdivia-Manchego M. Science of the Total Environment 272 (2001) 217-230. 
[12] Ielsch G., Cushing M. E., Combes Ph. and Cuney M. J. Environmental Radioactivity 101(2010), 813-820.

[13] EPA (1993): U.S. Environmental Protection Agency: EPA's map of radon zones. Report, 402-R93-071, September 1993. http://www.epa.gov/radon/zonemap.html (last accessed 14 June 2011).

[14] United Nations. Sources and effects of ionizing radiation. United Nations Scientific Committee on the Effects of Atomic Radiation, 2000 Report to the General Assembly, with annexes.

[15] EURDEP. http://eurdep.jrc.ec.europa.eu/ (last accessed 14 June 2011). 